\title{
The Ecological Cluster as an Energy Transition Engine
}

\author{
Nya Imane \\ PhD Cand., University Mohamed V, Souissi, Rabat \\ Elgraini Mina \\ Pr., University Mohamed V, Souissi, Rabat
}

\begin{abstract}
The occurrence of successive economic crises, strong competitive pressures, and the degradation of natural and ecological resources are some of the major threats that make energy transition the new holy grail of the 21st century. This awareness of the urgency of the situation opens of the possibility for adopting an alternative approach - one of alliances, partnerships, and cooperation within the framework of exchange and sharing. This is, as Harari put it, the secret of the success of man. It can contribute sure to the goal of sustainable economic development. In line with this, new organizational forms have emerged, with the restructuring of the economy, integration of the principles of sustainable development, and development of renewable energies and clean technologies. These so-called Cleantech ecosystems, clusters focused on sustainable development projects, serve the dual function of at once contributing to economic growth and the attractiveness of an economy for investors and preserving the environment.
\end{abstract}

Keywords: energy transition, clean technologies, sustainable development, ecological grouping, territorial governance

\section{Introduction}

In the face of current environmental challenges such as environmental degradation, climate change, and loss of biodiversity, it is necessary to shift from an energy system based on non-renewable energy to one based on renewable energies and clean technologies.

The 1987 Brundtland Report, the 1992 World Conference on the Environment in Rio de Janeiro, and the adoption of the Kyoto Protocol in 1997 were all occasions on which the urgency of the looming ecological and environmental disaster was brought to the attention of states.

Hence the need to turn to an alternative model combining economic growth and 
environmental preservation.

In particular, the transition to renewable energy requires switching to an alternative model that restructures the current system and reorders the priorities of the various stakeholders.

It is necessary to adopt a new energy system that reconciles economic and environmental motives through the development of green technologies and specific mechanisms that can reduce negative impacts on the environment.

The success of the energy transition process is dependent on the implementation of governance because the consideration of environmental constraints is influenced by the forms of interaction and cooperation between the various stakeholders.

The green cluster is an alternative model that can help make the energy transition process smoother. Its implementation could particularly enable more effective resource management at different levels (i.e., energy, solar, recycling, waste treatment, ecoconstruction, etc.).

The purpose of this paper is to demonstrate the close relationship between energy transition and the green cluster and to present arguments supporting the hypothesis that the establishment of the green cluster is a driver of energy transition.

A review of the literature reveals the importance of the analysis of theories of territorial organizational structures and industrial ecology for a better understanding of green ecosystems.

In fact, such structures are based on a combination of geographical, organizational and cognitive proximity, enjoying competitive advantages, a reinforced innovation process, and an easy flow of information.

The question that remains to be addressed is to what extent the establishment of the green cluster contributes to the success of the ecological transition process.

In responding to this query, this paper first presents a review of the literature, looking in particular at theories concerning territorial organizational networks and the definition of hypotheses. Then, it analyzes the links between the green cluster and ecological transition by analyzing the points that the two have in common. Finally, the paper presents the benefits of the ecological cluster and a few case studies from around the world where it has effectively been implemented.

\section{Material and Method}

Insofar as the question of methodology is concerned, this paper draws on documentary research and bibliographical study in order to enrich the analysis of the theoretical concepts necessary to the understanding the approaches being discussed, notably those relating to territorial networks of organization and industrial ecology. 
The paper also presents pioneering examples from around the world of environmentally friendly policies, emphasizing the specific characteristics and strengths of each model.

\section{Theoretical and Conceptual Framework}

The increasing occurrence of ecological and economic crises reveals the fragility and the limits of the current economic model. It goes without saying that challenges such as climate change, the scarcity of natural resources, and environmental degradation require the implementation of an alternative model.

Theoretical analysis shows a neglect of the spatial and environmental dimension, such that the theories concerning the location of economic activities do not include explicit references to the territory.

By way of example, Fordism, as highlighted by Alain LIPIETZ (1995) ignored the ecological question and the territorial dimension. Post-Fordism, for its part, has fully taken into account the dimension of space and location.

The Fordist crisis has contributed to the substitution of the model of economic development based on standardization and mass production, and based on big business, to a model based on flexible specialization through a spatial concentration of small businesses.

Hence, there is a close relationship between the principles of sustainable development, territorial organizational networks and economic performance (LIPIETZ 1995)

It is only in the period of post-Fordism that taking into account local factors, space and territorial anchorage became important. Following the crisis of Fordism, new forms of organization appeared based on industrial agglomerations. (LIPIETZ 1995).

Theoretical approaches to territorial organizational networks can be presented as follows:

\begin{tabular}{|l|l|l|l|}
\hline $\begin{array}{l}\text { Territorial } \\
\text { organizational } \\
\text { networks }\end{array}$ & Theorists & Definition & Specificities \\
\hline $\begin{array}{l}\text { Industrial } \\
\text { District } \\
\text { Marshallian }\end{array}$ & $\begin{array}{l}\text { Alfred } \\
\text { MARSHALL } \\
(1920)\end{array}$ & $\begin{array}{l}\text { Geographically located Division of work } \\
\text { production system based on Atmosphere conducive to } \\
\text { an internal division of labor|learning } \\
\text { between small and medium- Reduction of transaction } \\
\text { sized companies specialized costs. } \\
\text { in different phases of the Existence of economies of }\end{array}$ \\
\hline
\end{tabular}




\begin{tabular}{|c|c|c|}
\hline $\begin{array}{l}\text { District } \\
\text { industrial } \\
\text { Italian }\end{array}$ & $\begin{array}{l}\text { Bagnasco } \\
(1977) \\
\text { Becattini } \\
(1979) \\
\text { Brusco } \\
(1982)\end{array}$ & 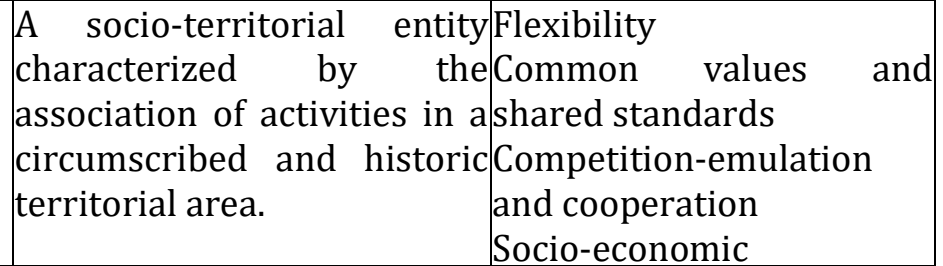 \\
\hline \begin{tabular}{|l|} 
Territorial \\
organizational \\
networks
\end{tabular} & Theorists & \begin{tabular}{|l|l} 
Specificities \\
\end{tabular} \\
\hline Cluster & Porter (1990) & $\begin{array}{l}\text { Geographic concentration of Competitive } \\
\text { related companies that cooperative relations } \\
\text { compete and cooperate with between firms located in } \\
\text { specialized suppliers, servicethe same area. } \\
\text { providers, related industry Value chain integrated } \\
\text { firms and associated territorially }\end{array}$ \\
\hline
\end{tabular}

It should be noted that this table does not represent an exhaustive list, and that there is a multitude of structures and a proliferation of concepts and designations (e.g., industrial pole, technological district, innovative environment, etc.). These forms of organization are mainly focused on the technology sector and more specifically information and communication technology (ICT). The rise of such structures in the industrial, technological and tourism fields suggests that their use may be compatible with green and sustainable sectors.

The theoretical analysis focuses on currents of thought that respond to this problem. Several theories were developed for this purpose, in particular the theories of growth and the theories of regulation, testifying to the importance and interest in this subject, from institutionalism, to the neoclassical current of thought and, more recently, industrial ecology.

It is important to analyze theoretical approaches that combine both economic growth and a transition to renewable energy. Indeed, the new territorial approaches underline the importance of the reconfiguration of the production system by adopting strategies based on the logic of partnerships and cooperation between the different actors in a given territory.

Theories relating to industrial ecology are in line with this approach, as they give a central place to the synergies between industrial players and the protection of the environment. The emergence in the late 1980s and early 1990s of theories of industrial ecology and eco-industrial systems is consistent with respect for principles such as the preservation of the environment. 
One author describes this as "a process of synergy of industrial actors for the purpose of closing the flows of materials and energies, in a logic of rationalization of the consumptions of natural resources".

The works of R. Frosch and N. Gallopoulos consider industrial ecology as inspired by the functioning of natural ecosystems.According to these two authors, this approach implies a balance of the incoming and outgoing flows of the industrial system, transformation of the waste of some in order to make new resources for others, renewal of available resources, the reduction of discharges and polluting emissions, and the reduction of energy intensity, losses and use of harmful substances.

This approach is based on actions such as recycling and the reduction of harmful substances in the environment (e.g., greenhouse gases, polluting emissions). Industrial ecology integrates the issues of sustainable development and the dimension of sustainability in the context of economic activities. (BEAURIN and BRULLOT 2011)

Thus, territorial organizational networks and sustainable development have points in common, and indeed economic growth can be compatible with the principles of sustainable development as evidenced by the rise and emergence of green growth.

In order to respond to the challenges of sustainable development, industrial ecology adopts a process of reconfiguration and reconstruction of territories by placing them in a sustainable perspective of economic activities.

This approach is based on constructive modes of coordination, on the games of actors and proximity. In fact, the forms of interaction between the various local actors are essential to the success of industrial ecology. It is deployed locally and is based on strategies aimed at economic and environmental rationality.

In line with this, the adoption of an alternative model such as the ecological cluster is based on a partnership approach integrating sustainable economic development, energy efficiency and the promotion of renewable energies. It contributes to the dynamisation of the energy transition process.

The industrial economy advocates a process of construction of territorial specification beyond the mere agglomeration of actors, which in turn means the modes of coordination and forms of proximity contribute to sustainable territorial development through the creation of new opportunities.

The involvement of different local actors is considered as an essential factor in the context of industrial ecology, and it is therefore necessary to identify the role of each local actor in order to facilitate the linking of the forms of interactions, alliances and the logic of cooperation between them.

\section{Ecological Cluster as an Instrument of Public Policy}

Energy transition requires the construction of a legal and regulatory framework 
integrating the sustainability dimension and taking into account the environmental and ecological effects in the implementation of public policies.

Indeed, the success of the alternative model depends on an integration of environmental motives and the strengthening of the legal framework through the implementation of transversal and global public policies able to face environmental challenges.

In the process of setting up an alternative model that breaks with the environmentally unfriendly production system, it is necessary to put in place public policies combining both incentives - such as ecological taxation - and regulations encouraging eco-friendly practices. The design of products, support for proactive environmental practices, and funding through grants and subsidies to encourage environmental preservations, combined with coercive measures sanctioning polluting technologies and systems can together go a long way in making an alternative model successful. (CHARLOT- VALDIEU et al 2013)

The establishment of the ecological cluster as a public policy strategy and instrument for the development of renewable energy and clean technology projects is coherent with these proposals.Such a structure contributes to the strengthening of sustainable economic development, the reduction of ecological risks and the carefully measured use of scarce natural resources.

The ecological cluster is an alternative approach aimed at reconciling both economic progress and environmental protection through the development of activities and projects with high added value and focused on green sectors.

There is a need to integrate public policies in a long-term vision by taking full account of the dimension of sustainability (and transversality) to face environmental threats. Action must be focused on the source of degradation.

Montalvo (2008) emphasizes the minimalism of environmental policies, suggesting that they are conservative and shortsighted. They have little incentive and focus mainly on preventive measures, whereas to achieve the desired results, it is necessary to adopt a sustainable approach, sustainable dynamics and a redesign of public policies.

In order to guarantee a successful ecological transition, it is necessary to include environmental and innovation policies by combining incentives and coercive measures so as to stimulate research and development expenditure and reduce negative effects on the environment. (HAMDOUCH and DEPRET 2009)

The success of the ecological transition and the green cluster require the reconfiguration of the production system by integrating the dimension of sustainability, and a complete restructuring of technological, political and institutional elements.

\section{Eco Innovation as a Catalyst for the Energy Transition Process}

Technological advances and the rise of so-called green and clean innovations play a 
considerable role in revolutionizing the potential for environmentally friendly growth. In fact, the success of the ecological transition depends on the process of innovation and advancement.

In this sense, the ecological cluster takes a central place in the innovation process; it corresponds to a model focused on the development of clean technologies and renewable energies (e.g., wind, solar, etc.). In fact, the existence of scientific actors, particularly universities and research centers within the green cluster, contributes to the creation of new knowledge and the dynamization of the innovation process. (COOKE 2010)

The ecological cluster is based on a sustainable integrated approach, and the concentration of different actors in a given area combined with cognitive proximity, contribute to the rapid circulation of information flows and consequently the strengthening of the critical mass of knowledge. Such proximity plays a role in strengthening the innovation process.

It can be considered as a range of innovative products and services aimed at optimizing the use of natural resources and renewing them in the long term. The ecological cluster is a radical change in the protection and preservation of natural resources through the use of clean and green technologies. (DAVIES 2013)

The establishment of the ecological cluster contributes to the revitalization of Ecoinnovation through the improvement of environmental sustainability, the reduction of the intensive use of natural resources by developing alternative technologies, reconciliation between the source and the environment, and the reduction of distances and consequently transport costs due to geographical proximity. (DADDI 2012)

The ecological cluster takes into account both economic considerations - by contributing to the performance and the improvement of the competitiveness and attractiveness of an economy - as well as environmental considerations, as evident from its focus on alternative measures.

It is part of an alternative approach that breaks with the polluting production system, contributing to the creation of sustainable economic dynamism and the facilitation of the energy transition through the development of high value-added activities with a special target: renewable energies and green technologies.

It also helps strengthen the positioning of companies operating in the eco-technology sectors by offering them international visibility and a critical mass of knowledge and skills. (HAMDOUCH AND DEPRET 2012) Such benefits are due to the existence of a real scientific base and the strong involvement of research and development actors.

The ecological cluster is part of a global approach to managing activities related to the environment (i.e., waste and wastewater treatment, recycling and purification), the renewable energy sector (i.e., wind, solar, biomass, photovoltaic, etc.) and also so-called 
alternative activities like eco-construction (e.g., sustainable buildings, eco-renovation, and energy management). (Rennings 2005)

Thus, such a structure constitutes an alternative model combining environmental and sustainability needs with efficiency and economic performance. It is based on a partnership approach involving a multiplicity of actors (i.e., companies, public actors, universities, research centers, etc.).

\section{Governance within the Ecological Cluster as an Institutional Framework of Interactions}

The resolution of environmental challenges and ecological problems requires the establishment of an institutional framework and a partnership approach integrating all economic, social and political factors.

The energy efficiency approach and the success of the ecological transition require the use of a concerted and collaborative approach. The green cluster is, it should be recalled, based on the involvement of a diversity of actors of different natures (i.e., companies, local communities, research centers, universities, etc.). This heterogeneity of stakeholders necessarily means there is a complexity inherent in the system, a divergence of interests which can in some cases even trigger conflicts. The use of governance is therefore essential to avoid failures and blockages threatening the success of the energy transition.

Colletis 2001 defines it as "a process of constructing compatibility between the different institutional proximities uniting geographically close actors (economic, institutional, social) in order to solve a local development project.

This definition highlights the importance of using such an approach and the role it plays in complex problem solving, such as the case of the issue of environmental effectiveness. It is part of a strategic approach contributing to the achievement of a shared vision.

Thus, environmental governance takes center stage in terms of sustainability management based on the mobilization of local stakeholders and the strengthening of alliances, logics of partnership and cooperation.

It constitutes an institutional framework guaranteeing the regulation and management of the various stakeholders necessary to deal with the scale of environmental risks and the success of the ecological transition.

\section{International Experiences in the Ecological Cluster}

Governments are becoming aware of the need to develop alternative models and adopt measures and mechanisms to deal with environmental problems. Indeed, as shown in the following table, several countries are developing strategies focused on integrating the sustainability dimension into their economic systems. This section introduces the pioneers of technological and environmental advances, including clean technologies and 
renewable energies.

Representative Table of the World Cleantech: (Report of the Ministry of Ecology, Energy, Sustainable Development and the Sea on global clusters in the field of eco-technologies)

\begin{tabular}{|c|c|c|c|}
\hline Clusters & Objectives & Specificities & Analysis \\
\hline $\begin{array}{l}\text { Envirolink } \\
\text { Northwest } \\
\text { (United } \\
\text { Kingdom) } \\
\text { operates in } \\
\text { the } \\
\text { following } \\
\text { areas: } \\
\text { Water } \\
\text { managemen } \\
\text { t, waste } \\
\text { recycling }\end{array}$ & $\begin{array}{l}\text { Stimulation of } \\
\text { activities } \\
\text { related to eco- } \\
\text { technologies } \\
\text { Support } \\
\text { innovation and } \\
\text { development of } \\
\text { innovative } \\
\text { products } \\
\text { Improving the } \\
\text { learning and } \\
\text { innovation } \\
\text { process }\end{array}$ & $\begin{array}{l}\text { Dynamism and } \\
\text { strong portability of } \\
\text { the scientific actor: } \\
\text { consortium of } \\
\text { universities } \\
\text { Important role } \\
\text { played by regional } \\
\text { development } \\
\text { agencies } \\
\text { Cooperation between } \\
\text { different } \\
\text { stakeholders (public, } \\
\text { private and scientific) } \\
\text { Programs such as: } \\
\text { low carbon } \\
\text { demonstration, } \\
\text { Biomass project to } \\
\text { achieve progress in } \\
\text { environmental } \\
\text { protection }\end{array}$ & $\begin{array}{l}\text { The cluster is characterized by an active } \\
\text { mode of governance integrating all the } \\
\text { stakeholders. } \\
\text { The existence of high potential in the } \\
\text { areas of recycling, energy-saving } \\
\text { technologies and a low-carbon economy. } \\
\text { The cluster has helped strengthen R \& D } \\
\text { capacity in the field of recycling } \\
\text { research and technology transfer. } \\
\text { The cluster contributed to strengthening } \\
\text { international visibility, identifying } \\
\text { opportunities related to eco-technology } \\
\text { markets. }\end{array}$ \\
\hline $\begin{array}{l}\text { Solar Valley } \\
\text { Mitteldeuts } \\
\text { chland } \\
\text { (Germany) } \\
\text { specializes } \\
\text { in solar } \\
\text { energy } \\
\text { throughout } \\
\text { its value } \\
\text { chain }\end{array}$ & $\begin{array}{l}\text { Maintaining the } \\
\text { technological } \\
\text { and scientific } \\
\text { advance } \\
\text { Introduction of } \\
\text { a quality } \\
\text { training offer } \\
\text { Strengthening } \\
\text { cluster } \\
\text { positioning and } \\
\text { branding } \\
\text { Attractiveness } \\
\text { of national and } \\
\text { international } \\
\text { funding }\end{array}$ & $\begin{array}{l}\text { Strong synergies } \\
\text { between the different } \\
\text { stakeholders } \\
\text { Major Grants for } \\
\text { Energizing the Solar } \\
\text { Energy Sector } \\
\text { Dynamism of the } \\
\text { environmental } \\
\text { technologies sectors } \\
\text { Existence of } \\
\text { structures ensuring } \\
\text { the control and } \\
\text { evaluation of the } \\
\text { cluster }\end{array}$ & $\begin{array}{l}\text { The cluster is characterized by the } \\
\text { existence of a real strategy for research } \\
\text { and innovation } \\
\text { Achieving real advances in solar cells } \\
\text { and equipment development (cost } \\
\text { savings). } \\
\text { The achievement of positive results in } \\
\text { energy efficiency and the growth of solar } \\
\text { technologies. } \\
\text { The dynamism of this cluster is evident, } \\
\text { as is its ability to foster international } \\
\text { cooperation and partnerships. } \\
\text { However, there is a need to strengthen } \\
\text { the steering and command structure by } \\
\text { providing it with stabilized legal power. } \\
\text { We must also strengthen the marketing } \\
\text { strategy for greater visibility and } \\
\text { attractiveness. }\end{array}$ \\
\hline
\end{tabular}




\section{Results}

The establishment of clusters tends to produce certain economic, social and environmental effects:

\subsection{Economic}

In clusters, the economic benefits are due to lower transportation costs because of geographical proximity. In addition, agglomeration of activities leads to increased productivity and skills.

Furthermore, some clusters help and accelerate business creation through the role played by incubators. These encourage companies to establish themselves by providing support and financial and technical monitoring.

Such an initiative is a virtuous circle, creating economic dynamism and local economic growth.

\subsection{Environmental}

The establishment of the ecological cluster contributes to a rational use of resources and reduces the consumption of extremely scarce natural resources. It also contributes to the development and growth of renewable energies and clean technologies that respect and preserve the environment.

In fact, in the case of the traditional model, the distances between the various stakeholders are substantial, therefore implying an increase in the quantities of fuels used and therefore a high energy consumption linked to this mode of transport. However in the case of the ecological cluster, there is geographical proximity and the externalities related to transport are reduced, thus contributing to the reduction of $\mathrm{CO} 2$ emissions.

The preservation of natural resources is possible thanks to a valuation approach and synergies, so the residues and waste of one company constitute the raw materials of another. Such actions contribute to recycling.

The organizational proximity embodied by the alliances, the logics of partnership and cooperation contributes to a rational use of resources and also to the preservation of waste. The cognitive proximity materialized by the exchange of information and knowledge plays an indispensable role in the creation of new products and processes, for example the promotion of new high-performance and less polluting technologies.

\section{3,3 Social}

Cluster presence helps to improve well-being by reducing poverty, unemployment and social inequalities. The cluster contributes to the improvement of the quality of life and the natural environment, in addition to the consolidation of the sense of belonging and identity.

Indeed, the establishment of the cluster based on an innovative approach contributes to 
the creation of new economic activity and therefore greater employment. This has the impact of improving the standard of living and creating wealth that reduces social disparities.

The attractiveness of a country is improved within the framework of the cluster because of the strengthening of the belonging and the local culture through the valorization of the specific local resources.

The establishment of the cluster does, however, face certain risks and threats that must be solved:

- Lack of financial means

- Reluctance of some stakeholders

- Existence of lobbies

- Poor financial results

- Stakeholder exit

- Heterogeneity of partners can lead to blockages and conflicts of interest

- Disengagement and exhaustion of stakeholders

- Managerial complexity

- Inertia and bursting

In the face of these challenges, it is necessary to put in place mechanisms and measures that can counteract these risks.

Thus the following table outlines the importance of governance, strategic and territorial management.

\begin{tabular}{|l|l|l|}
\hline & Governance & Strategic and territorial management \\
\cline { 2 - 3 } & $\begin{array}{l}\text { Governance } \\
\text { The need to put in place an institutional } \\
\text { framework guaranteeing steering and } \\
\text { management actions for all stakeholders. } \\
\text { Indeed, the existence of a structure } \\
\text { ofmanagement will put an end to } \\
\text { factors } \\
\text { situations of blockages, divergences of } \\
\text { interests, even to conflicts, thus } \\
\text { privileging the collective interest. } \\
\text { The establishment of a system of } \\
\text { regulation and frameworks of relations } \\
\text { between the various stakeholders. }\end{array}$ & $\begin{array}{l}\text { The need to carry out an upstream } \\
\text { teritorial diagnosis aimed at identifying } \\
\text { strengths and weaknesses, but also a } \\
\text { categorization of all stakeholders } \\
\text { highlighting strategic priorities. } \\
\text { It is also necessary to allocate the resources } \\
\text { essential to the success of the cluster (i.e., } \\
\text { financial, human, technical, etc.) } \\
\text { The use of communication campaigns to } \\
\text { attract new players, and to limit the } \\
\text { reluctance of certain actors. }\end{array}$ \\
\hline
\end{tabular}

The analysis of global clusters demonstrates the important role played by the latter in 
reinforcing technological advances in renewable and green energies. Indeed, the establishment of the cluster contributes to the improvement of the learning and innovation process and consequently the development of new energies that are more respectful of the environment and less energy consuming, even at a certain cost.

The energy cluster benefits from the support of the various stakeholders through forms of cooperation and synergies that contribute to real dynamism and the promotion of projects focused on environmental technologies.

The green cluster and energy transition are closely linked. Together, they promote the transition from a highly polluting production system to an alternative system reconciling economic and environmental motives.

They are based on strengthening the process of innovation and learning by giving a central place to eco-innovation, so that it offers more sustainable technologies and products.

The green cluster and energy transition cannot achieve the expected results without the mobilization and involvement of all stakeholders, be they public, private or scientific, in an institutional framework based on the principles of governance, exchange, and information sharing.

Therefore, the green cluster can be likened to an energy transition engine, capable of providing an institutional, legal and technological base to guarantee the success of the transition towards sustainable economic development.

\section{Conclusion}

The current socio-economic crisis and the ecological impasse require the reconfiguration of the current production system by adopting an alternative model centered on the question of sustainability.

To this end, the ecological cluster is a model based on the involvement of a host of public and private actors and also civil society with a common goal of sustainable economic development respectful of the principles of sustainable development. These actors develop alternative pathways in contrast to traditional production systems.

Cooperation and the logics of partnership between the various stakeholders (e.g., companies, universities, local communities, etc.) are essential to carry out such an approach.

The green cluster can be considered as an engine of ecological transition combining both the dynamisation of the economic system and the strengthening of the ecological system.

Energy transition is dependent on a restructuring of the economy and a reorganization of stakeholders' priorities by putting in place an alternative model focused on the principles of development and the logic of partnership and cooperation present within ecological clusters. 


\section{References}

[1] Beaurain, C., \&Brullot. S. (2011). L'ecologie industrielle comme processus de developpement territorial: une lecture par la proximite. Revue d'Economie Regionale \& Urbaine, (2), 313-340.

[2] Benko, G. (2000). Developpement durable et systemes productifs locaux.

[3] Chabault, D., \& Tours, I. A. E. (2007). La gouvernance des reseaux territorialises d'organisation: revue de litterature d'un concept emergeant. Cahiers de Recherche du Centre d'etudes et de recherches en management de Touraine (CERMAT).

[4] Charlot-Valdieu, C., Debizet, G., Da Cunha, A., \&Outrequin, P. (2013). Mutation ecologique et transition energetique. Vers la ville intelligente?. URBIA. Les Cahiers du developpement urbain durable, (15), 13-25.

[5] Daddi, T., Tessitore, S., \& Frey, M. (2012). Eco-innovation and competitiveness in industrial clusters. International Journal of Technology Management, 58(1/2), 49-63.

[6] Daumas, J. C. (2007). Districts industriels: du concept a l'histoire. Revue economique, 58(1), 131-152.

[7] Davies, A. R. (2013). Cleantech clusters: transformational assemblages for a just, green economy or just business as usual?. Global Environmental Change, 23(5), 1285-1295.

[8] Decouzon, C., \&Maillefert, M. (2012). Evaluer des projets d'ecologie industrielle sur des parcs d'activite: des synergies au territoire. Geographie, economie, societe, 14(4), 411-434.

[9] Depret, M. H., \&Hamdouch, A. (2009). Quelles politiques de l'innovation et de l'environnement pour quelle dynamique d'innovation environnementale?. Innovations, (1), 127-147.

[10] Deutz, P., \& Gibbs, D. (2008). Industrial ecology and regional development: ecoindustrial development as cluster policy. RegionalStudies, 42(10), 1313-1328.

[11] Forest, J., \&Hamdouch, A. (2009). Les clusters a l'ere de la mondialisation: fondements et perspectives de recherche. Presentation generale. Revue d'economie industrielle, (128), 9-20.

[12] Hamdouch, A., \&Depret, M. H. (2012). Green entrepreneurship networks and clusters: when the local requires the global. In RSA Global Conference, Beijing (Vol. 148).

[13] Hamdouch, A., \&Depret, M. H. (2012). Sustainable development policies and the geographical landscape of the green economy: actors, scales and strategies. 
Finisterra, 47(94).

[14] Leducq, D., \&Lusso, B. (2011). Le cluster innovant: conceptualisation et application territoriale. Cybergeo:European Journal of Geography.

[15] Michaux, V. (2011). Les determinants de la performance des gouvernances territoriales. Le cas des strategies concertees de developpement durable des territoires. Revue frangaise de gestion, (8), 35-60.

[16] Pecqueur, B. (2006). Le tournant territorial de l'economie globale. Espaces et societes, (1), 17-32. 